Archived version from NCDOCKS Institutional Repository http://libres.uncg.edu/ir/asu/

Ellis, Thomas B. (2009) "I Love You, I Hate You: Toward a Psychology of the Hindu Deus Absconditus," International Journal of Hindu Studies 13:1, 1-23. (ISSN: 10224556)

\title{
I Love You, I Hate You: Toward a Psychology of the Hindu Deus Absconditus Thomas B. Ellis
}

Psychological studies of Hindu religion and culture routinely stress a difference between "East" and "West." Whether this difference reflects a certain Hindu pathology (Carstairs 1961; Spratt 1966; Masson 1980; Kakar 1981) or normative developments relative to each culture (Roland 1988; Kurtz 1992), the seemingly uncontested consensus is that Hindu India nurtures a "collective self." Though generally finding many of these studies quite fascinating and often persuasive, I wish to draw attention to a dimension that is routinely overlooked. In an effort to paint with broad strokes a culture preoccupied with psychological mergers and integrations, many authors fail to take note of particular forms of bhakti, or devotion, that appear to contest such a preoccupation. The structural features of viraha bhakti (love-in-separation) and virodha bhakti (love-manifest-asenmity) in particular reflect and influence a psychological construction of self that is not merged in or integrated with the other: viraha bhakti and virodha bhakti present Hindu god images that model a separated-individuated self.

Because any one religious tradition is clearly over-determined, definitive psycho- logical interpretations remain elusive. This is certainly the case with viraha bhakti and virodha bhakti. While maintaining that the two devotional models similarly reflect a separatedindividuated self, I nevertheless present competing interpretations. The competition issues from the difference between interpreting god imagery as either corresponding with or compensating for the realities of childhood (Kirkpatrick 2005). In the former case, the religious model repeats culturally normative developments; in the latter, the religious model deviates from culturally normative developments. Whether or not the compensation is psychologically deviant is an altogether different issue.

The two interpretations I present here share a common point of departure in what the psychoanalytic anthropologist Stanley N. Kurtz calls the "new psychology of Hinduism" (1992: 6). Kurtz's new psychology is based upon what many contemporary ethnographers consider to be a "more" accurate portrait of Hindu childrearing practices. Where the "classical" account addresses the Hindu mother's wholesale indulgence of her child, the new account stresses physical indulgence accompanied by emotional absence. With regard to viraha bhakti and virodha bhakti, the compensatory interpretation argues for the facilitation of an individuated sense of self 
that compensates for the culturally normative immersion of the self in the Hindu group, an immersion the mother's emotional absence ostensibly facilitates. The love or hatred of the absent Hindu deity betrays in this way a certain love of self. Alternatively, the correspondence interpretation suggests that viraha bhakti and virodha bhakti correspond with the inner world of the Hindu child as he or she negotiates the relationship with the physically present, yet emotionally absent mother. Despairing love for and then angered abandonment of the absent deity corresponds precisely with the documented tactics children employ when forced to deal with the absent caregiver (Bowlby 1973).

The discussion unfolds over three sections. I first present a brief review of two psychological theories I find most pertinent to the present project, attachment theory and object relations theory. I choose these two among the many because they have been the privileged theories for previous psychological studies of Hindu mergers and integrations (Maduro 1976; Kakar 1981) ${ }^{1}$ As separation and individuation are antithetical to merger and integration, a certain consistency in theoretical approach commends itself. I proceed from there to an admittedly brief discussion of Hindu god imagery. My intention is not, to be sure, to engage in a detailed analysis of any one particular image. I am not interested in the minutiae of particular images; studies of such minutiae abound. My intention is rather to identify the structural condition of particular Hindu god images that most reflect the ideal-type relationships between self and other that the theories address. Universal patterns of relationship inform the Hindu constructions of deity, constructions that reflect upon the relationship between devotee and deity and, by direct extension, self and other. The final section applies object relations theory and attachment theory to the Hindu god imagery. 2 In so doing, the discussion necessitates a consideration of the contested topic of Hindu childrearing practices. The present project thus follows Kurtz's methodology: "By juxtaposing childrearing practices with myth and ritual, a picture of the inner meaning of development can be built up" (1992: 178). Indeed, the application of object relations theory and attachment theory to Hindu myths and childrearing ethnographies yields tentative answers to the question I pursue here: What is the psychology of the Hindu deus absconditusl

\section{Theory: Attachment and Object Relations}

Attachment theory addresses primarily human infant ethology. Based on the work of the British psychiatrist John Bowlby $(1969,1973,1980)$, attachment theory documents the proximity seeking strategies of the human infant. Human infants - and adults consistently and predictably seek out proximity to a stronger, wiser other - the attachment figure - in moments of threat, distress, or fear of abandonment. Humans are, biologically speaking, irreducibly gregarious. Gregariousness has its risks. The attachment figure, for whatever reasons, may not be available. Relationship may be denied. Accordingly, the human animal has an evolved suite of behaviors 
to draw upon that help negotiate the vicissitudes of relationship (Ainsworth, Blehar, Waters, and Wall 1 978).

Though some wish to disaggregate attachment theory from object relations theory (Granqvist 2006), others find that the two complement one another (Fonagy 1999, 2001). I tend toward the latter position. As an etho logical perspective, attachment theory necessarily studies observable behaviors (Eibl-Eibesfeldt 1989). The human animal, however, enjoys an additional dimension - the inner world. Humans not only behave, they also have thoughts and fantasies concerning their behaviors (Greenberg and Mitchell 1983: 186-87). Because of the biological predisposition to gregariousness, one of the more predominant issues animating human fantasy is sociality. Accordingly, concerns pertaining to relationships often dominate the inner world. The fantasies and affects attending such concerns are the domain of object relations theory. Object relations theory proposes that the sense of self and other - that is, the selfrepresentation and the object representation - are co-constitutive (Greenberg and Mitchell 1983). True selfhood is thoroughly relational. Amid the various "objects" an individual encounters throughout the lifespan, one object in particular takes on an unequalled importance: the primary caregiver or attachment figure. On this score, attachment theory and object relations theory are clearly in agreement.

The primary caregiver is that first other in the "basic biological situation," that is, "the period during which the child and the parent are locked in elemental care- giving, carereceiving interactions" (Faber 2004: 17; see also Bollas 1987). According to both theories, the image of that first other, an image including not only the physical traits, but more importantly the affective nature of the relationship itself - what attachment theory calls the internal working model and what object relations theory calls the object representation - continues to influence the individual's perceptions, expectations, and affections regarding others throughout life. Due to the indelible effects of that first relationship, an individual never truly encounters a stranger again. We help create the objects we meet - including god, of course (Winnicott 1971). Significantly for the present discussion, the cognitive ability to distinguish an object as different from self develops over time.

According to the child psychiatrist Margaret S. Mahler and her colleagues Fred Pine and Anni Bergman (2000: 44), the human infant begins its psychological life without the capacity to distinguish between self and object: an initial psychological monism or autism characterizes the neonate's inner world (see also Kakar 1981: 52- 53). Following upon this initial autism, the infant apparently enjoys a symbiotic phase. During this period, the infant sees all others - and especially the mother - as extensions of self. Self and mother are locked in a symbiotic embrace. According to Mahler, the psychological birth of the human infant - a birth not coincident in time with the physical birth - rests precisely on a rupturing of this symbiosis. The self- representation depends upon an initial negation of a totality, a negation catalyzing the protracted process of what Mahler famously calls "separation-individuation." 
Mature psychological health, according to Mahler, Pine, and Bergman results from an uncompromised break with the $(m)$ other.

The developmental psychologist Daniel N. Stern raises some doubt regarding the primacy of Mahler's symbiosis. He suggests that merger experiences are dependent on an already established sense of self: "The evidence... suggests that the capacity to have merger-or fusion-like experiences as described in psychoanalysis is secondary to and dependent upon an already existing sense of self and other" (Stern 1985: 70; see also Rochat 2001). Prior to the emergence of what he calls the "core self," and in advance of any Mahlerian symbiotic experiences, Stern argues that there is an "emergent self," that is, "the infant can experience the process of emerging organization as well as the result" (1985: 45; emphasis added). The emergent self apparently predates all other psychological experiences, including the symbiotic one. For Stern, Mahler's symbiotic moment is the result of the emergent or core self-collapsing the boundary between itself and the other. Stern thus challenges the developmental schema Mahler proposes, but he does not deny - and this is most important for the present discussion - the capacity for symbiosis and merger.

This is in fact Fred Pine's (2000: ix) reply to Stern. Pine argues that there are indeed moments when nondifferentiation from the mother constitutes the infant's experience. Though the experience of fusion/symbiosis/merger may not find support in developmental psychology as a primary experience, it is all the same recognized as a potential and deeply influential occurrence in the inner world of the infant. The critical question thus concerns the extent to which these brief merger experiences, which object relations theory, attachment theory, and developmental psychology acknowledge, affect adult fantasy. Pine asserts that they affect it greatly:

Are such experiences, if brief, sufficient to account for the significance of merger wishes or merger anxieties in later life? To this I answer with a clear "yes "...The lasting significance of developmental events need in no way be highly correlated with their duration: intense affective states - be they deeply satisfying and reliable, or traumatic and intrusive or prematurely ruptured - may well have an impact on memory, wish, fantasy formation, and anxiety far out of proportion to their simple duration ....

The sense of merger is in fact consistent with the reality of the infant's experience at times, so there is no reason to think that the more objectively accurate perceptions will automatically transcend them. This does not occur uniformly even in adults, in whom self-other differentiation may be thought to be much more securely established (2000: ix-x; emphasis added).

Stern's work is persuasive, Pine's response compelling. We need not presume a developmental stage of primary symbiosis to maintain the presence of symbiotic moments and their impact on the fantasy lives of children and adults. What I find most significant for the present discussion is Pine's recognition of both "merger wishes" and 
"merger anxieties." Infant as well as adult fantasy life has the capacity not only to long for, but also to flee from merger experiences. Such fantasies clearly inform the structural dimensions of god imagery.

From the perspective of object relations theory and attachment theory, idiosyncratic fantasy, familial relationships, and extended culture influence the construction of any one god image. The god image is in this regard what the object relations tradition calls a transitional object (Winnicott 1971; Rizzuto 1979). The psychologist of religion William B. Parsons explains:

The God-Representation is a representational collage, a "work of art" over determined on a variety of levels, being constructed from extant cultural materials, the full spectrum of developmental phases and abstract ideational components. Culture mediates the components of religion through family, church, and school. Clinical studies show that the God-Representation can be composed of paternal and maternal elements and reflect pre-Oedipal as well as Oedipal developmental configurations (1999: 157).

If the sense of self is intimately tied to the representation of the other, then god, as the nonobvious object par excellence, is the infinitely malleable object capable not only of reflecting but also informing and responding to the self $s$ developmental needs. To be sure, "the sense of self and its reality is directly and vitally connected with the God representation.... The elaboration and reworking (or lack of reworking) of the parental imagos into a God representation... is... deeply related to the endless process of separation-individuation from the parents, and also to newer identifications with them" (Rizzuto 1979: 51).

Despite the rather widespread consensus amid the object relations community concerning the universality of separation-individuation, anthropologists working with Indian material present confounding data. Kurtz (1992) and Suzanne R. Kirschner (1996) argue in particular that Mahler's theory of separation-individuation is culturally determined. According to Kurtz and Kirschner, Hindu India does not privilege or promote individuation. Hindu India promotes "separation-integration" (Kurtz 1992: 273). While separation from the primary caregiver is a universal element in human psychological development, culture apparently dictates the normative outcome of such separation. Where modern Western culture emphasizes individuation, Hindu India presses integration (a process perhaps equally applicable to Japanese culture [see Roland 1988]). Thus, the psychoanalyst of religion Ana- Maria Rizzuto' s emphasis on separation-individuation in relation to the Hindu god representation requires emendation. The Hindu god representation is deeply related to the process of separation-integration, or so we would be led to believe. The seductive simplicity of such dichotomous thinking notwithstanding, Hindu god images are, I argue, illusory transitional objects, deeply related to either separation- integration or separationindividuation (Nagpal 2003; Ramanujan 1999; Obeyese- kere 1981; Kakar 1989). 


\section{Description: Hindu God Images}

The impression one often gets, especially today, is that Hinduism is an essentially monistic tradition (King 1999). The Advaita Vedanta, in particular, is often privileged as the prototypical Hindu religious worldview. The cross-cultural psycho-analyst Alan Roland suggests that without an appreciation of the centrality of the Advaita Vedanta, "it is virtually impossible to comprehend Indian psychological makeup, society, and culture" (1988: 289). While monistic interests are clearly prevalent in Hindu India, Roland overstates the case. Moreover and rarely com- mented upon, the Advaita Vedanta is not all of a psychological piece. In this regard, Roland seemingly misidentifies disparate psychologies. Because there are two types of "oceanic feeling" (Masson 1980; Parsons 1999), I argue there are two competing psychologies. Roland's observation regarding the centrality of the Advaita Vedanta is significantly incomplete. For instance, where the nineteenth-century Bengali saint Ramakrsna and the Chandogya Upanisadic studenthero Svetaketu apparently immerse themselves in the other's totality, the subject of the Astdvakrasamhita subsumes all others in itself. ${ }^{3}$ Oceanic totality represents either the other's grandiosity or the self $s$ grandiosity. Identifying which of the two is most prevalent in Hindu India - something I believe Roland fails to do - would greatly mitigate, among other things, the routine assignation of pathology to unitive mysticism, a topic to which we shall return. For now, and despite the popularity of monistic god imagery, the Hindu tradition(s) clearly makes room for god imagery that is anything but monistic (O'Flaherty 1980: 87-88; Milner 1994: 208). There are indeed models of bhakti which unequivocally contest the merger fantasy. Viraha bhakti and virodha bhakti are two such models.

Viraha bhakti is love-in-separation. The virahini, or viraha bhakta, pines for the god to return to presence. The god, however, intentionally withdraws from the devotee. In the Bhdgavata Purdna (10.32.20-21), for instance, Krsna withdraws for the sake of his devotees' intense devotion: "I do not love even the people who love me, so that their attachment may continue...! have concealed myself... for the sake of your devotion to me" (Hardy 1983: 536). The devotees themselves question whether Krsna will ever return: "Will he ever place his arm... upon our heads?" (Bhdgavata Purdna 10.47.21; Bryant 2003: 197). The heartfelt longings for unity with Krsna at the center of viraha bhakti notwithstanding, these passages present a god image in direct contrast to that of the oceanic feeling. Here the deity is nowhere to be found. He has withdrawn, and the community of devotees bemoans his withdrawal. In certain devotional moments, the devotee even claims the fires of separation will consume her being (Hawley 1984: 105). While one should not casually dismiss such protestations, I propose that it is the absence of the deity's presence that ought to capture our attention. Krsna' s messenger Uddhava seemingly confirms this when he addresses the gopis: "By your separation, you have shown wholehearted love for Adhoksaja" (Bhdgavata Purdna 10.47.27; Bryant 2003: 198). In a similar vein, the historian of Hindu religions Wendy Doniger O'Flaherty incorporates a passage from E. M. Forster's A Passage to India to illustrate viraha bhakti: "The god is a deus absconditus or otiosus. As Professor Godbole explains to 
Mrs. Moore, the worshipper imagines that he is a gopi who sings to Krishna, 'Come to me,' but the god refuses to come.... He may come in 'some other song' but not in our song, not now' " (1980: 122; emphasis in original). This is important. In certain instances, the god returns to the devotee. However, for some devotees the god is not coming back, not in this song, not now - perhaps never. I argue that it is precisely this structural separation that constitutes viraha bhakti.

If longing-in-separation characterizes viraha bhakti, virodha bhakti presents a similar structural separation but one marked this time not by love but by enmity. Virodha bhakti refers to those forms of devotion wherein the devotee expresses disaffection for the god. The Tamil poet Cuntaramurttinayanar provides some telling verses: "I don't call to him as my mother. I don't call to him as my father. I thought it would be enough to call him my lord - but he pretends I don't exist, doesn't show an ounce of mercy. ...Can't we find some other god?" (1 Patikam 4.2; O'Flaherty 1988: 170). Here the poet represents the god not only as withdrawn, but more importantly as unresponsive. Elsewhere he bitterly notes: "You can sell me off, but I am nobody's pawn - I chose to be mastered by you! I did nothing wrong, yet you blinded me - why, lord, did you take my eye? The disgrace is wholly yours. If you won't restore my other eye - then I wish you luck; go away!" (4 Patikam 95.2; O'Flaherty 1988: 176; emphasis in original). Once again expressing displeasure, Cuntaramurttinayanar finally dismisses the god altogether. Even within the Bhdgavata Purdna (10.47.16-17), similar dissatisfactions with the deity find expression: "The fickle Krsna abandoned those who had abandoned children, husbands and other people in this world for his sake. Why then should I be recon- ciled with him? His disposition is cruel.... Enough of friendship with that dark- complexioned one" (Bryant 2003: 197).

There is no question concerning the disparate affective states viraha bhakti and virodha bhakti represent. The former bemoans the withdrawal of the god while the latter angrily encourages it. Such affective disparity notwithstanding, I invite us to consider that the two devotional models conjointly oppose Hinduism's monistic images in their explicit representation of an existent yet absent god. Because the psychological tradition of commentary upon Hinduism is replete with considerations of unitive states, it is this structural separation of deity and devotee that ought now to command our attention. I propose that the devotee who bemoans the withdrawal of or angrily dismisses Krsna (or \&iva as the case may be) is for whatever reasons motivated to represent Krsna as withdrawn or worthy of dismissal in the first place. What, psychologically, explains the construction of the Hindu deus absconditus?

\section{Redescription: Toward a Psychology of the Hindu Deus Absconditus}

Sudhir Kakar argues that the vicissitudes of fusion and separation constitute the "the essential psychological theme of Hindu culture" (1981: 34). As essential, this psychological theme necessarily pervades the disparities between Hindu unitive mysticism and Hindu devotional separation. Proposing that Hindu India generally privileges fusions and mergers (Kakar 1981; see also Roland 1988, 1996), Kakar notes 
that in clinical practice his Indian patients often suffer from fears of separation from attachment figures, explicitly suggesting that the threat of loneliness is most troubling (1981: 85). For many, such fears and anxieties appear to encourage the pursuit of mystical experiences. Herein resides the infamous assignation of psycho- pathology. The unitive experience is a pathological retreat to the infantile scene.

In Samadhi, the saint has by the progressive annihilation of all external and internal distracting stimuli, achieved the feat of voluntary regression to the prenatal state before his first encounter with the outside world. He is lowered into a pit, the womb of earth, and once enclosed there he lives forever unchanging in a timeless bliss of union with his creator: a triumph of phantasy over the reality-scene (Carstairs 1961: 161).

Kakar adds,

The vicissitudes of separation have been... at the heart of psychoanalytic theorizing on mysticism. The yearning to be reunited with a perfect, omnipotent being, the longing for the blissful soothing and nursing associated with the mother of earliest infancy (perhaps as much an adult myth as an infantile reality), has been consensually deemed the core of mystical motivation (1991 : 24-25).

While such a position may reflect the heart of psychoanalytic theorizing on mysticism, we must not lose sight of the fact that such psychoanalytic theorizing may be overly influenced by cultural preferences. Perhaps Western mysticism reflects a certain return to the blissful soothing of earliest infancy, but this may not be the case for Hindu India. A potentially flawed interpretation of Hindu childrearing practices produces a misidentified ontogenesis of Hindu moksa, a misidentification facilitating an erroneous imputation of pathology to all forms of mysticism.

G. Morris Carstairs (1961) provides one of the first psychological accounts of childrearing practices in Hindu India. He generally portrays the Hindu mother as overly indulgent with her child, a thesis supported by both Philip Spratt (1966) and Kakar (1981). According to Carstairs, Spratt, and Kakar, the Hindu mother shelters her child from day-to-day frustrations, the very sort of frustrations object relations theorists posit to be of inimitable value to the separation-individuation process. Indeed, the repeated experience of minor frustrations is precisely what facilitates the gradual and ostensibly normative separation from the mother. In the absence of such a gradual introduction to frustration, the Hindu child continues to live in an almost magical world of immediate emotional and physical gratifications.

The main emphasis in the early years of childhood is avoidance of frustration.... An Indian child is encouraged to continue to live in a mythical, magical world for a long time. In this world, objects, events and other persons do not have an existence of their own, but are intimately related to the self and its mysterious moods... a state of being in which the whole world, including other people, is experienced as a part of the self and within one's spontaneous control (Kakar 1981: 103,105,128). 
The developmental problem associated with such prolonged indulgence is that it ill equips the child for the eventual separation from the mother, a separation that then amounts to "a narcissistic injury of the first magnitude" (Kakar 1981 : 128).

Classical psychoanalytic accounts of Hindu personality development suggest that with the introduction of the adult world of societal proscription and law, an introduction classically accompanying the Hindu rite of initiation for the boy (for example, the upanayana) and marriage for the girl, the child is abruptly taken from the world of indulgent mothers and placed in the world of cool, dharmic regulations. The child is ostensibly torn from symbiotic bliss and thrown into a world of fastidious distinctions and separations. Carstairs, Spratt, and Kakar argue that this unprepared for, abrupt separation from the mother ends in an infantile identification with her, a passive stance in regard to others who are expected to treat the subject as he or she was treated in childhood. It is for these reasons that the Hindu childrearing pattern nurtures a narcissistic personality, that is, a personality prone to see external reality as an extension of self (Spratt 1966). All three authors thus identify as pathological a general Hindu failure to separate, a failure based on maternally indulgent child- rearing practices. Consequently, moksa must reflect this pathology, or such is the substance of Kurtz's (1992) criticism of the classical account of both Hindu mysticism and Hindu childrearing practices.

The current debate regarding Hindu childrearing practices concerns the nature of Hindu maternal indulgence. Ethnographic data documenting breastfeeding through the first three or four years of life in combination with observations of the mother sleeping next to her children through the first several years of life attest to a certain physical indulgence. According to the classical account, emotional indulgence attends this physical indulgence (Kakar 1981: 54-55). The Hindu mother complements her physical ministrations with emotional investment. Kurtz, following Alan R. Beals (1962), Leigh Minturn and John T. Hitchcock (1966), Geoffrey Gorer (1967), Renaldo Maduro (1976), and Margaret Trawick (1990), and further corrobo- rated by Susan C. Seymour (1999) and Alan Roland (1994), contests precisely this claim. Kurtz suggests that the Hindu mother is physically present but emotionally absent. Such dynamics constitute the "new psychology of Hinduism" (Kurtz 1992: 6).

Kurtz, and others, argue that the ethnographic data do not support the love relationship between mother and child characteristic of Kakar's interpretation of Hindu childrearing practices. While there seems to be an indulgence with respect to physical ministrations, the emotional complement is apparently missing. It is precisely the absence of emotional indulgence that forestalls the narcissism the classical authors putatively detect: "The difficulty with this idea of pervasive narcissism in Hindu family life... is that neither the mother nor the other family members are engaged in an intimate exchange or reflection of emotions with the child" (Kurtz 1992: 41). Minturn observes in fact that the Hindu mother's interaction with her child would seem to be anything but emotional stimulation: "Adult interaction with babies is generally aimed at producing a cessation of 
response rather than a stimulation of it" (1966: 1 10; emphasis added). Such practices are not, to be sure, exclusive to Hindu India. The anthropologist Robert A. LeVine notes that many non- Western cultures similarly engage in physical indulgence and emotional withdrawal when tending their young. He observes that behaviors such as empathic eye contact and smile elicitation do not factor into these various cultures and their childrearing practices (LeVine 1977: 23).

The point for Kurtz is that the Hindu mother - through such emotional withdrawal intentionally prepares her child for the inevitable separation from her and the subsequent integration in the group, the overlooked player in the Hindu child's inner world. He in fact goes to great lengths to suggest that the mother "gently" pushes her child toward the group of in-law mothers:

The family group, and not merely the individual mother and her child, lies at the core of this suggested model of Hindu child rearing. From this point of view, much of a Hindu mother's behavior toward her child is designed to gently push him away from the relationship with her and toward a sense of immersion in, or unity with, the family at large. Similarly, the behavior of family members other than the mother is meant to exert a kind of pull on the child to drive him away from an exclusive tie to the mother (Kurtz 1992: 60-61).

Seymour similarly notes, "While nursing, a mother responds physically to her child but withholds empathic attention, thus encouraging the child to seek emotional satisfaction in relationships with others, not in an exclusive relationship with her" (1999: 82). According to Kurtz and Seymour, the preoedipal, emotional separations the child experiences at the hands of the mother prepare him for the forthcoming ritual separations, thereby reducing the tension and anxiety of Kakar's upanayana while simultaneously nurturing the expectation of rewards attendant upon inclusion in the adult group.

Conceding for the present the new psychology of Hinduism, the question concern- ing the child's perception of the Hindu mother's partial indulgence immediately arises. To suggest that the child understands the reasoning behind the mother's behavior would certainly attribute too much cognitive maturity - not to mention emotional detachment to the child. In the absence of such emotional detachment and cognitive maturity, the possibility of affective hurt must be entertained, or at least such is the Indian psychiatrist Salman Akhtar's criticism of Kurtz's work. Akhtar notes that a child who experiences the mother's emotional absence must suffer: "In proposing that the unempathic and 'impersonal character' of maternal care propels the child toward 'mature immersion' in the larger family group, Kurtz betrays an astonishing lack of understanding of how traumatic such mothering can be for the child" (1997: 1017). Kurtz has not, according to Akhtar, resolved the issue of painful separation from the mother by insisting on her "gentle push" toward the group prior to the upanayana (or other such ritual separations). In fact, even Kurtz acknowledges the priority of this injury: "While the child no doubt develops a strong emotional attachment to the mother as a result of the physical 
gratification she provides, the mother does not respond by setting up a Western-style loving, emotional partnership" (1992: 44). Moreover, and despite Kurtz's suggestion that the group of in-law mothers lessens the hurt felt by the child, the preeminent attachment theorist John Bowlby $(1969,1973)$ argues to the exact contrary that polymatry actually intensifies monotropy; that is, a group of mothers serves to intensify and not mitigate the child's desire for attachment to the primary caregiver. It would thus seem that at least a significant aspect of the Hindu child's preoedipal world rests with an unrequited longing for emotional reciprocity, a longing so strong that it potentially amounts to a longing for unity.

The classical psychological interpretation of moksa is that it is a return to the symbiotic embrace of childhood. Moksa ostensibly corresponds with the blissful state of union with the mother, in this way undoing the process of separation- individuation. Kakar writes, "The theme of isolation and its transcendence... constitutes the core of the moksha ideal. This theme has its ontogenetic source in... the interactions between mothers and infants in Indian society... elaborated in Hindu mythology as the persistent nostalgic wish for the benevolent presence of the 'good mother' as she was experienced in infancy" (1981: 85). Elsewhere, he qualifies this emphasis on infancy when interpreting Ramakrsna's mysticism: "The mother was unavailable at a time when his anxiety about separation, and its convergent depression, were at their apex.... The unity Ramakrishna aimed for is, then, not the mergerlike states of the infant at the breast... but the ending of separation striven for by the toddler" (Kakar 1991: 26-27; emphasis added). Though Kakar addresses disparate psychosocial stages in these two passages, all the same he maintains a commitment to a correspondence interpretation: moksa corresponds with an early childhood reality, either symbiotic or preseparation. In both instances, the repetition of the childhood scene is understood to be a retreat from an adult reality, in which case a subtle intimation of psychopathology lingers. Kurtz, to the contrary, proposes that the moksa experience is a "spiritualized" version of the individual's culturally normative integration in the group. In other words, moksa corresponds not with the infantile reality of the young Hindu child, but with the mature immersion of the older child in the extended family: 'The solution, exemplified by the ecstatic's merger with the collective gods, is voluntary renunciation of infantile connection in favor of a merger with the group" (Kurtz 1992: 186). By virtue of this interpretation, Kurtz contests the assignation of pathology to unitive mysticism precisely because such a position disregards the culturally relative normalcy of the mature group sense of self. Despite their disparate interpretations, both Kakar and Kurtz remain in this way wedded to a correspondence interpretation, altogether overlooking the possibility that moksa may just as easily provide psychological compensation.

The compensatory interpretation suggests that the monistic god image compensates for the shortcomings of early childhood. Accordingly, Advaita Vedanta's moksa conceivably reflects the compensatory efforts of the devotees to surmount the dynamics of Hindu childhood. The prevalence of merged identities of the type where the self loses itself in the other may rest in the Hindu mother's emotional unavailability. In other words, those 
longing for a submersion of self in other may betray a psychological discomfort with the realities of Hindu childrearing practices. Such is the substance of the work of the Indologist and psychoanalyst J. Moussaieff Masson (1976), who suggests that an abandonment depression often informs monistic mysticism. He argues that many of the themes found in Hindu religious and philosophical literature reflect depressive states: "The concern voiced ubiquitously by the ascetic in Indian literature - vairagya or nirveda, 'world weariness' or 'disgust' - is an oblique reference to the affective disorder known as sadness when mild, depression when strong, and melancholia when severe" (Masson 1976: 618). Masson provocatively suggests elsewhere that all ascetics "have suffered from harsh and unloving parents" (1976: 623; see also Deutsch 1975). Combining this statement with one from The Oceanic Feeling (Masson 1980), the potential outlines of the affective impact of Hindu childrearing practices upon the child emerge: "Behind every depression is a memory of being alone, of being left" (71). This would partially account for Kakar's repeated encounter with analysands anxious about separation. A certain pathological reaction to the absence of maternal empathy may drive the search for mystical integration with the other. Of course, such an interpretation would leave out of consideration the moksa experience reflected in the Astdvakrasamhita, that is, the mystical experience wherein the self subsumes the other.

According to the anthropologist Ronald Preston Rohner (1975), "rejecting parent- ing styles," including specifically those forms of routine, physical ministrations accompanied by empathic absence here associated explicitly with Hindu India, often eventuate in a worldview where the external reality is seen as deceptive and wrong. Here of course Advaita Vedanta's doctrine of maya comes immediately to mind.

The underlying mistrust which seems to cloud so many of my informants' adult personal relationships may well be derived from the phantasy of a fickle mother who mysteriously withholds her caresses and attentions from time to time... at weaning the child's emotional insecurity is suddenly intensified.... His confidence is shattered and from now on he mistrusts everything that pretends to constancy.... To such a feeling the concept of all-pervading Maya seems appropriate, if not inevitable (Carstairs 1961: 158).

Juxtaposing the recent discussions of Hindu childrearing practices with the Advaita Vedanta's devaluation of the untrustworthy world and its monistic longings, the possibility arises that the Hindu child and/or mystic suffers from an abandonment depression and seeks to mollify the affects of such depression by engaging in a fantasy regarding the grandiose self. If the childrearing practices in Hindu India explicitly proscribe the mother's empathic gaze, then Rizzuto's comment becomes particularly apt: "Bewilderment, narcissistic rage, vengeful grandiose wishes (hidden in fantasy or enacted in adaptive or maladaptive behavior), and identification with God are the common adaptational reactions to make the painful state of not being mirrored as oneself tolerable" (1979: 186). To be sure, aggression against others often attends 
cosmic narcissism (Masson 1980). Significantly, this is precisely how Kakar reads Saiva god imagery:

[The] earliest reparation in which the boy turns away from the disappointing external world and seeks comfort and a sense of control in such defensive manoeuvres (sic) as 'I do not need anyone,' 'I am sufficient unto myself,' and 'I am perfect.' This compensatory activation of the grandiose self finds its mythological counterpart in the very conception of Shiva - remote from the world, isolated and self-sufficient in his mountain hideout of Kailasha (1981: 156; emphasis added).

Narcissistic grandiosity forestalls future harm issuing from the abandoning object(s) by ultimately denying that object's reality

As seen here, the two types of monistic Hindu god imagery reflect disparate psychological tactics. The first type - submersion of self in other - is seemingly overdetermined. As Kurtz argues, this type may correspond with a psychologically healthy immersion of self in the adult group, in which case there is nothing pathological here. By contrast and again allowing Kurtz's model to inform us, the same submersion of self in other may reflect a compensatory longing for what was not in fact the case, in which case there may be a tinge of psychopathology. After all, Kurtz's reading of monistic mysticism depends upon immersion in a collectivity of gods, and often the monistic experience is characterized not by unity with a collection but rather an individual deity, for example, Ramakrsna's immersion in Ma Kali. The second form of monistic god imagery presents, on the other hand, a god image in which the self takes on grandiose proportions. There is an explicit sense that nothing else exists but the self. Interestingly, and unlike the first form of monism, the second does not seem to lend itself to the correspondence model. Rather, the grandiose self lends itself to two compensatory interpretations. For instance, if the psychological developmental norm is to immerse oneself in the group, then this would clearly betray a certain psychopathology. Like Kakar's Siva, the individual denies the very reality of the frustrating, preoedipal object. Even more significantly from the Kurtzian perspective, the group is denied existence. While this is to a certain extent a compelling interpretation, there is another. Complementing the potential pathology implied by the first compensatory interpretation, the second suggests a psychologically healthy alternative.

Roland suggests that devotional practices are meant to extricate the individual from immersion in the larger family. Though the normative developmental outcome reflects a tie to the larger group - what Roland calls the "familial self (1988) - there are moments when individual Hindus seek to escape the group.

What has been profoundly overlooked is that however much these religious modes of worship and experience are related to the intense mother-child symbiotic relationship, the actual religious experience enables the person to become increasingly individuated, differentiated, and separated from the intensely emotional, 
familial involvements. This experience thus becomes an essential counterpoint to the familial self (Roland 1988: 296; emphasis added).

Elsewhere Roland notes, "There is... considerable privacy and often secrecy involved in individual spiritual practices, key ingredients in the separation process...I must posit it [that is, the effort to realize the spiritual self] as the central theme of Indian individuation throughout life" (Roland 1988: 309-310; emphasis added). According to Roland, the grandiose individuation associated with the second type of Hindu monism reflects the individual's desire to extricate himself from the web of family relationships. This is not psychopathological, but in fact quite salubrious. Roland however betrays an inconsistency. While he suggests that the spiritual practices are ways for the Hindu practitioner to disengage the extended family and this en route to a separated, individuated inner world, he undermines this reading by his larger account of bhakti.

In bhakti devotional worship, various facets of symbiosis-reciprocity involved in hierarchical intimacy relationships become clearly accentuated. Intense emotional connectedness and reciprocal affective exchanges, a sense of we-ness, and permeable ego boundaries are all intensely involved in bhakti worship. The devotee seeks through intense emotionality to be merged with the god, goddess, or incarnation... and in turn through the merger expects the reciprocity of divine bliss (Roland 1988: 295).

The trouble I have with Roland's observations is that they complement the problematic methodological individualism of classical psychoanalysis. If Freudians are seduced by the siren of individualism, it would appear that many authors working with non-Western material are similarly seduced by the siren of the group. Roland persistently pursues Hindu merger. Needless to say, this smacks as much of Orientalism as the assignation of pathology to the un-individuated Hindu. As Rizzuto so clearly argues, the world of religious fantasy is a world of objects. The question for psychologists of religion concerns the relationship of the self to this inner-object-world. According to Roland, the individuated Hindu is really not so. The Hindu may disengage the familial, but this apparently in the name of engaging the esoteric familial. The bhakta forgoes familial merger for divine merger. In which case, I am left asking, are there really no separatedindividuated individuals in Hindu India? Are merger anxieties pertinent only to the individualistic West?

Moksa elicits, at least for some, a merger anxiety (Milner 1994: 223, 225). Despite the contemporary enthusiasm for Hinduism's monistic soteriologies, some Hindus desire a continued sense of self, a sense dependent upon an opposition to the other. Viraha bhakti and virodha bhakti are models ministering to such desires. The absent object is the object representation par excellence for a self-representation in which one's sense of self is eternally preserved from the identity-eliding experience found in Advaita Vedanta's god imagery. In this sense, Hinduism's theology of istadevata (chosen deity) provides the participant community the leeway necessary to accommodate their varying psychological needs (Rao 2005: 302). The panoply of Hindu god images and their 
devotional models provide the idiom in which Hindu devotees may locate their own senses of self, that is, a chosen devotional model becomes what Gananath Obeyesekere (1981) refers to as a personal symbol. ${ }^{4}$ Like their monistic complement, however, viraha bhakti and virodha bhakit are equally overdetermined.

Viraha bhakti and virodha bhakti are complex forms of devotion lending them-selves both to compensatory and correspondence interpretations. One compensatory reading suggests that the images reflect the satisfaction of a deep wish. For example, viraha bhakti unquestionably protests a longing for the other to return. This protestation may even become so exaggerated as to suggest the utter annihilation of the one so separated. All the same, the passionate protestations of love for the absent Krsna and the desire for him to return may dissimulate the opposite wish which the god image actually fulfills. Krsna is present as absent. The psychological payoff is that the gopi/devotee knows he or she is not Krsna or better yet, that Krsna is "not-me." An absent Krsna safeguards the devotee's identity. Thus in the moments of dire devotion to the deity, that is viraha bhakti, the deep motivation may be narcissistic: a profound love of self-funds the profound love for the absent other. Viraha bhakti is, at least from this perspective, love (of self)-in-separation (from other), a heretofore undetected reversal of the object of love in bhakti. Rizzuto comments in regard to one of her analysands: "She wants no union with God: 'I don't know what it means to be united to God but I think it means I will have to be a part of him and I don't feel I want to be a part of him.' One may reflect whether this is a defensive reaction against fusion" (1979: 171-72). I propose we extend Rizzuto's reflection to viraha bhakti: viraha bhakti's god image potentially reflects a defensive reaction against fusion. Despite Roland's suggestion that through "bhakti devotional worship... the devotee seeks. ..to be merged with the god" (1988: 295), the exact opposite is occasionally the case, that is, the devotee seeks not merger but separation. Significantly, what keeps this form of narcissism from falling into psychopathology is that the other is not annihilated as it is in grandiose narcissism. The other maintains an existence in viraha bhakti, reflecting a healthy sense of self as opposed to other.

Separation as a healthy, defensive maneuver is similarly accomplished by aggressive means. While viraha bhakti is pervaded by the sentiment, "I love you," virodha bhakti presents the sentiment, "I hate you." Cuntaramurttinayanar is particularly prevalent here. Again, from an object relations perspective, Cuntaramurttinayanar's sense of betrayal and concomitant anger may in fact be the fulfillment of a wish. Unrequited love and outraged antagonism are both psychical mechanisms for maintaining a distance between self and other (Bollas 1987; Balint 1953). Note the psychotherapist James F. Masterson's interpretation of one of his analysand's behavior: "When the wish for union and merger became too intense, he would attack the idealized person because only by attack could he separate and preserve his sense of self (1988: 215). Similar dynamics may inform virodha bhakti. The self-representation that favors an individuated identity has at its disposal an object representation worthy of attack. Kakar's clinical work with Pran supports such an interpretation: 
Relatively early in his analysis, Pran became aware of the underlying pattern in his behavior. Going to work, traveling, drinking and, of course, sexual intercourse, are 'manly' activities to which he is greatly drawn. They are, however, also experienced as a separation from the mother which gives rise to anxiety till he must come back to her, in food and sleep. He must recurrently merge with her in order, as he puts it, to strengthen his nervous system.... It took a longer time for Pran to become aware of the terror of his mother's overwhelming invasiveness inspired in the little boy and his helpless rage in dealing with it.... He realized that all his 'manly' activities were not only in pursuit of individuation as a man... but also because they would lacerate the mother.... Often, as he lies there, abusing the mother, with a blissful expression on his face reflecting her close presence, I cannot help but feel that this is nindastuti [a.k.a., virodha bhakt] worship of a divinity through insult, denigration and contempt, which is one of the recognized relationships of a Hindu devotee with a divinity (1999: 226-27).

Virodha bhakti is according to this compensatory interpretation a form of object representation in the service of preserving an individuated sense of self in the face of a potentially encompassing object: aggression constructs an externality that aids the individuation of self (Greenberg and Mitchell 1983: 355). "' 'I am' demands space, often in confrontation with the 'I am' of others" (Nagpal 2003: 65). The object representation, and in this case, the god image worthy of abuse, plays this role. Like viraha bhakti, virodha bhakti is conceivably a compensatory, narcissistic defense against merger anxieties.

While the compensatory interpretations suggest themselves, it is equally plausible that viraha bhakti and virodha bhakti correspond. Bhaktas may represent through religious literature and poetry the emotional dynamics of an unresponsive caregiver in early childhood. Viraha bhakti may be seen in this way as the first step toward virodha bhakti. If Indian children must negotiate an identity in the face of an empathically absent mother, then perhaps viraha bhakti and virodha bhakti reflect first the child's longing for the other and secondly the child's anger toward the other so withdrawn. According to attachment theory, this is in fact the two-step process towards abandoning the unavailable other (Bowlby 1973, 1980). At first, the child pines for the caregiver's attention. Absence does indeed make the heart grow fonder, at first. Recall, Krsna withdraws in order for the devotees' devotion to grow (Hardy 1983: 536). Despite Kurtz's position, this accurately reflects the dynamics of attachment. An unavailable other intensifies, not mitigates the self's desires. If emotional reciprocity is not forthcoming, the child despairs. In direct contrast to Kurtz's model, which suggests that the self abandons the primary other for the secondary others, we notice that the gopis are forlorn for they have abandoned the secondary others for attachment to the other, who in turn abandons them. The gopi/child at first foregoes relationships to the extended family members in order to love only the mother. Of course, from Uddhava's perspective, the gopis show love for Krsna by their separation. Uddhava's position is much more in line with Kurtz's suggestion, that is, the child - from the mother's 
perspective to be sure - demonstrates his or her love for the withdrawn mother precisely by allowing the separation. Of course, like the child, the gopis do not seem convinced of Uddhava's message.

Recalling now Cuntaramurttinayanar's virodha bhakti, we find some similarly interesting suggestions. Cuntaramurttinayanar proclaims that he did nothing wrong, yet the god blinded him all the same. Blinding is a classical psychoanalytic euphemism for castration. If we put this through the Kurtzian mill, we find that the god/ mother blinds the child, that is, severs the child's libidinal ties to her, and this without the child having had the opportunity to develop such ties in a transgressive way - Cuntaramurttinayanar did nothing wrong. Perhaps most telling, however, is that both the gopis and Cuntaramurttinayanar eventually get to the point where they say "enough." After all, the gopis first bemoan Krsna' s withdrawal and then eventually suggest his abandonment. As attachment theory predicts, the child/devotee finally abandons the unresponsive other. In both instances, the devotee wishes to find some other god/parent. This is precisely Kurtz's point. By her emotional unavailability, the mother forestalls the development of the libidinal ties the child so desires and in so doing forces the child to choose a substitute object. Both the gopis and Cuntaramurttinayanar eventually call for the same abandonment of the deus absconditus and otiosus. Perhaps in these instances, the god image corresponds with the poets' own parent(s) who in childhood "neglected" their emotional pleas in favor of group orientation. While this accurately reflects Kurtz's model, where it departs is in the clear indication of hurt and despair first felt by the child/devotee before he or she moves on to another: Kurtz is too ready to discount anguish and despair.

As a last option - though one I do not find particularly compelling - perhaps the bhakti literature betrays the child's revenge. John Stratton Hawley notes in this regard that the gopis are traditionally women and they are the ones who are now suffering the separation from the male deity. By identifying with the deity, the devotee-poet who establishes the suffering of the woman is in effect punishing the mother-substitute for her own withdrawal (Hawley 2000: 248). This is a stretch. It is much more commonplace for devotees to identify with the gopis, in which case I maintain that the god images of viraha bhakti and virodha bhakti more likely reflect either a desired absence of the other in favor of a compensatory individuation or a truly bemoaned withdrawal of the other corresponding with the realities of Hindu childrearing practices revealed in contemporary ethnographies.

\section{Conclusion}

As the product of cultural idiom, family life, and private need, the Hindu god image is a transitional object particularly suited to the negotiations regarding the sense of self and other, that is, "the polarity between fusion and separation," "the essential psychological theme of Hindu culture" (Kakar 1981: 34). Though the foregoing argument applies explicitly to Hindu god imagery, it equally applies to all constructions of deity. I argue that the examination of any particular god image and its attendant relationship sheds 
interpretive light on the psychological needs of the religious practitioner. The prediction thus emerges that those who favor an uncompromised individuation will gravitate toward those religious traditions and their god images that maintain a distinction between devotee and deity; for example, the historical theisms. Alternatively, those who favor a sense of self enmeshed with the other - group or otherwise - will gravitate toward those religious traditions and their god images that facilitate a fantasy of merger. Whether these respective fantasies correspond with or compensate for childhood and adult realities is clearly relative to the cultural milieu in question. The larger point I wish to make here - and it is one that would be too obvious to mention if it were not for the many texts repeatedly intimating otherwise - is that no one culture pursues only one psychological developmental pathway. While it may be the case that Hindu India leans towards the "fusion pole," it is clear from the devotional material that several individuals find it attractive that on occasion the powerful other(s) is not immediately present. The pathology of such god imagery rests on whether or not the other is merely absent (healthy) or altogether annihilated. An annihilated other reflects narcissistic rage; an absent other reflects healthy individuation.

The foregoing is, to my knowledge, the first attempt at an object relations and attachment theoretical interpretation of viraha bhakti and virodha bhakti. Such a project hopefully makes persuasive the argument that Hindu god imagery clearly betrays the psychological complexity of Hindu India, in this way offsetting the rather fashionable tendency to pigeonhole the religion and culture in a category characterized by fusion as opposed to the West's individuation. Indeed, viraha bhakti and virodha bhakti are two devotional models predicated precisely on the maintenance of an individuated sense of self in opposition to an eternally other other. Adjudicating definitively whether such individuation is correspondent with or compensatory for Hindu childhood must await another day.

\section{Notes}

1. It may also be noted here that authors working in the field of cross-cultural psychology endorse the application of object relations theory to non-Western cultures. For instance, the American psychoanalyst Alan Roland notes: "From cross-civilizational psychoanalytic work it is evident that psychoanalytic drive theory needs serious amending. The vicissitudes of superego and ego-ideal development and early object relations, all related to culture, are just as or more central to character development, later behavior, and the kinds of defenses that are emphasized than those of the drives alone" (1996: 142-43). The preeminent Indian psychoanalyst Sudhir Kakar similarly notes, "the relational models, with their different understanding of human development... are congruent with the dominant cultural orientation and experiences of people living in the non-Western societies. The confinement of psychoanalysis to Western societies during the last eighty years and its stagnation... in India and Japan over decades may well be 
due to the individualistic premises of the drive psychology model which clash with the dominant cultural orientation of non- Western societies" ( 1 997: 43).

2. Similar studies using the Core Conflictual Relationship Theme measure have been undertaken with respect to the Tanakh and Christian Bible. See Popp, Luborsky, Andrusyna, Cotsonis, and Seligman (2002); Popp, Luborsky, Descoteaux, Diguer, Andrusyna, Kirk, and Cotsonis (2003, 2004).

3. Ramakrsna's biography contains the following confession: 'The buildings with their different parts, the temple, and everything else vanished from my sight, leaving no trace whatsoever, and in their stead I saw a limitless, infinite, effulgent Ocean of Consciousness... to swallow me up! I was panting for breath. I was caught in the rush and collapsed" (Nikhilananda 1984: 13-14). Likewise the Chandogya Upanisad famously notes, "O good-looking one, from the ocean these eastward rivers flow east, and these westward rivers flow west, and they return to the ocean. As they become (once again) the ocean, they do not recognize that 'I am this (river), I am that (river)' " (6.10.2; my translation). In both instances, the devotee is like a stream pouring into the ocean's totality. Alternatively, the Astdvakrasamhita notes, "You are not the body nor is the body in you. You are neither the enjoyer nor the doer. You are true consciousness, forever the witness and indifferent (to the affairs of the world). Go with happiness.... In you, (who are) the infinite ocean, the rising and falling of waves neither increase nor decrease your being" (15.4, 11; my translation). Here oceanic identification is reversed. Now the devotee is the ocean which subsumes all others. The two models betray different psychological comportments, topics to be addressed below.

4. Obeyesekere defines personal symbols as follows: "cultural symbols whose primary significance and meaning lie in the personal life and experience of individuals. ...The symbol is recreated anew by the individual.... The personal symbol... has unconscious, deep motivation and intracommunicative significance" (1981: 44-46).

References Cited

Ainsworth, Mary D. Salter, Mary C. Blehar, Everett Waters, and Sally Wall. 1978. Patterns of Attachment: A Psychological Study of the Strange Situation. Hillsdale: Lawrence Erlbaum Associates.

Akhtar, Salman. 1997. "Review of Stanley N. Kurtz's All the Mothers are One: Hindu India and the Cultural Reshaping of Psychoanalysis." Journal of the American Psychoanalytic Association 45, 3: 1014-19.

Balint, Michael. 1953. Primary Love and Psycho- Analytic Technique. New York: Liveright Publishing Corporation. 
Beals, Alan R. 1962. Gopalpur: A South Indian Village. New York: Holt, Rinehart and Winston.

Bollas, Christopher. 1987. The Shadow of the Object: Psychoanalysis of the Unthought Known. New York: Columbia University Press.

Bowlby, John. 1969. Attachment. New York: Basic Books.

bowlby, John. 1973. Separation: Anxiety and Anger. New York: basic books.

Bowlby, John. 1980. Loss: Sadness and Depression. New York; Basic Books.

Bryant, Edwin F. 2003. Krishna: The Beautiful Legend of God. New York: Penguin.

Carstairs, G. Morris. 1961 [1957]. The Twice- Born: A Study of a Community of HighCaste Hindus. Bloomington: Indiana University Press.

Deutsch, Alexander. 1975. "Observations on a Sidewalk Ashram." Archives of General Psychiatry 32, 2: 166-75.

Eibl-Eibesfeldt, Irenaus. 1989. Human Ethology: Foundations of Human Behavior. New York: Aldine De Gruyter.

Faber, M. D. 2004. The Psychological Roots of Religious Belief: Searching for Angels and the Parent-God. Amherst: Prometheus Books.

Fonagy, Peter. 1999. "Psychoanalytic Theory from the Viewpoint of Attachment Theory and Research." In Jude Cassidy and Phillip R. Shaver, eds., Handbook of Attachment: Theory, Research, and Clinical Applications, 595-624. New York: The Guilford Press.

Fonagy, Peter. 2001. Attachment Theory and Psychoanalysis. New York: Other Press.

Gorer, Geotirey. 1967. Himalayan Village: An Account of the Lepchas of Sikkim. New York: Basic Books.

Granqvist, Pehr. 2006. "On the Relation Between Secular and Divine Relationships: An Emerging Attachment Perspective and a Critique of the 'Depth' Approaches." The International Journal for the Psychology of Religion 16, 1: 1-18. Greenberg, Jay R. and Stephen A. Mitchell. 1983. Object Relations in Psycho-analytic Theory. Cambridge: Harvard University Press.

Hardy, Friedhelm. 1983. Viraha-Bhakti: The Early History of Krishna Devotion in South India. New Delhi: Oxford University Press.

Hawley, John Stratton. 1984. Sur Das: Poet, Singer, Saint. Seattle: University of Washington Press. Hawley, John Stratton. 2000. "Krishna and the Gender of Longing." In Nancy M. Martin and Joseph Runzo, eds., Love, Sex, and Gender in the World Religions, 239-58. Oxford: Oneworld. 
Kakar, Sudhir. 1981. The Inner World: A Psycho- Analytic Study of Childhood and Society in India. New Delhi: Oxford University Press.

Kakar, Sudhir. 1989. Intimate Relations: Exploring Indian Sexuality. Chicago: University of Chicago Press.

Kakar, Sudhir. 1991. The Analyst and the Mystic: Psychoanalytic Reflections on Religion and Mysticism. New Delhi: Viking.

Kakar, Sudhir. 1997. Culture and Psyche: Psychoanalysis and India. New York: Psyche Press.

Kakar, Sudhir. 1999. "Clinical Work and Cultural Imagination." In Jeffrey John Kripal and T. G. Vaidyanathan, eds., Vishnu on Freud's Desk: A Reader in Psychoanalysis and Hinduism, 216-32. New Delhi: Oxford University Press.

King, Richard. 1999. Orientalism and Religion: Postcolonial Theory, India and 'the Mystic East. * London: Routledge. Kirkpatrick, Lee A. 2005. Attachment, Evolution, and the Psychology of Religion. New York: Guilford Press.

Kirschner, Suzanne R. 1996. The Religious and Romantic Origins of Psychoanalysis: Individuation and Integration in Post-Freudian Theory. New York: Cambridge University Press.

Kurtz, Stanley N. 1992. All the Mothers are One: Hindu India and the Cultural Reshaping of Psychoanalysis. New York: Columbia University Press.

LeVine, Richard A. 1977. "Child Rearing as Cultural Adaptation." In P. Herbert Leiderman, Anne Rosenfeld, and Steven R. Tulkin, eds., Culture and Infancy: Variations in the Human Experience, 15-28. New York: Academic Press.

Maduro, Renaldo. 1976. Artistic Creativity in a Brahmin Painter Community. Berkeley: Center for South and Southeast Asia Studies, University of California.

Mahler, Margaret S., Fred Pine, and Anni Bergman. 2000 [1975]. The Psychological Birth of the Human Infant: Symbiosis and Individuation. New York: Basic Books.

Masson, J. Moussaieff. 1976. "The Psychology of the Ascetic." Journal of Asian Studies>5 A: 6W-25.

Masson, J. Moussaieff. 1980. The Oceanic Feeling: The Origins of Religious Sentiment in Ancient India. Dordrecht: D. Reidel Publishing.

Masterson, James F. 1988. The Search for the Real Self: Unmasking the Personality Disorders of Our Age. New York: Free Press.

Milner, Murray, Jr. 1994. Status and Sacredness: A General Theory of Status Relations and an Analysis of Indian Culture. New York: Oxford University Press. 
Minturn, Leigh and John T. Hitchcock. 1966. The Rajputs of Khalapur, India. New York: Wiley. Nagpal, Ashok. 2003. "Cultural Continuity and Change in Kakar' s Works: Some Reflections." In Dinesh Sharma, ed., Childhood, Family, and Sociocultural Change in India: Reinterpreting the Inner World, 48-87. New Delhi: Oxford University Press.

Nikhilananda, Swami, trans. 1984 [1942]. The Gospel of Sri Ramakrishna. New York: Ramakrishna-Vivekananda Center.

Obeyesekere, Gananath. 1981. Medusa's Hair: An Essay on Personal Symbols and Religious Experience. Chicago: University of Chicago Press.

O'Flaherty, Wendy Doniger. 1980. Women, Androgynes, and Other Mythical Beasts. Chicago: University of Chicago Press.

O'Flaherty, Wendy Doniger, ed. 1988. Textual Sources for the Study of Hinduism. Chicago: University of Chicago Press.

Parsons, William B. 1999. The Enigma of the Oceanic Feeling: Revisioning the Psychoanalytic Theory of Mysticism. New York: Oxford University Press.

Pine, Fred. 2000 [1975]. "Preface." In Margaret S. Mahler, Fred Pine, and Anni Bergman, The Psychological Birth of the Human Infant: Symbiosis and Individua- tion, vii-xiii. New York: Basic Books.

Popp, Carol A., Lester Luborsky, Tomasz P. Andrusyna, George Cotsonis, and David Seligman. 2002. "Relationships Between God and People in the Bible: A Core Conflictual Relationship Theme Study of the Pentateuch/Torah." Psychiatry 65,3:17996.

Popp, Carol A., Lester Luborsky, Jean Descoteaux, Louis Diguer, Tomasz P. Andrusyna, Dan Kirk, and George Cotsonis. 2003. "Relationships Between God and People in the Bible, Part II: The New Testament, with Comparisons with the Torah." Psychiatry 66, 4: 285-307.

Popp, Carol A., Lester Luborsky, Jean Descoteaux, Louis Diguer, Tomasz P. Andrusyna, Dan Kirk, and George Cotsonis. 2004. "Relationships Between God and People in the Bible, Part III: When the Other is an Outsider." Psychiatry 67, 1: 26-37.

Ramanujan, A. K. 1999. 'The Indian Oedipus." In T. G. Vaidyanathan and Jeffrey J. Kripal, eds., Vishnu on Freud's Desk: A Reader in Psychoanalysis and Hinduism, 1 09-1 36. New Delhi: Oxford University Press.

Rao, D. G. 2005. "Manifestations of God in India: A Transference Pantheon." In Salman Akhtar, ed., Freud Along the Ganges: Psychoanalytic Reflections on the People and Culture of India, 271-308. New York: Other Press.

Rizzuto, Anna-Maria. 1979. The Birth of the Living God: A Psychoanalytic Study. Chicago: University of Chicago Press. 
Rochat, Philippe. 2001. The Infant's World. Cambridge: Harvard University Press. Rohner, Ronald Preston. 1975. They Love Me, They Love Me Not: A Worldwide Study of the Effects of Parental Acceptance and Rejection. New Haven: HRAF Press.

Roland, Alan. 1988. In Search of Self in India and Japan: Toward a Cross-Cultural Psychology. Princeton: Princeton University Press.

Roland, Alan. 1994. Psychoanalysis in India and Japan: The Work of Sudhir Kakar and Takeo Doi." The Psychoanalytic Review 81,4: 717-37.

Roland, Alan. 1996. Cultural Pluralism and Psychoanalysis: The Asian and North American Experience. New York: Routledge.

Seymour, Susan C. 1999. Women, Family, and Child Care in India: A World in Transition. New York: Cambridge University Press.

Spratt, Philip. 1966. Hindu Culture and Personality: A Psycho-Analytic Study. Bombay: Manaktalas.

Stern, Daniel N. 1985. The Interpersonal World of the Infant: A View from Psychoanalysis and Developmental Psychology. New York: Basic Books.

Trawick, Margaret. 1990. Notes on Love in a Tamil Family. Berkeley: University of California Press.

Winnicott, D. W. 1971. Playing and Reality. New York: Basic Books. 